\title{
Clinical significance of tumor necrosis factor receptor 2 in middle and lower thoracic esophageal squamous cell carcinoma
}

\author{
DONG YANG ${ }^{1}$, RUIDONG LI ${ }^{1}$, HUILI WANG ${ }^{1}$, JUNYE WANG $^{1}$, YE LI $^{2}$, \\ $\mathrm{HONGBO} \mathrm{WANG}^{3}$, WEI WANG ${ }^{4}$ and ZIFENG LIU ${ }^{5}$ \\ ${ }^{1}$ Oncology Department, Affiliated Hospital of Jining Medical University, Jining, Shandong 272029; \\ ${ }^{2}$ Pathology Department, Feixian People's Hospital, Linyi, Shandong 273400; ${ }^{3}$ Pathology Department, \\ Juye County Hospital of Traditional Chinese Medicine, Heze, Shandong 274900; ${ }^{4}$ Pathology Department; \\ ${ }^{5}$ Digestive Department, Affiliated Hospital of Jining Medical University, Jining, Shandong 272029, P.R. China
}

Received August 19, 2017; Accepted May 31, 2018

DOI: $10.3892 / \mathrm{ol} .2018 .8998$

\begin{abstract}
High expression and role of tumor necrosis factor receptor 2 (TNFR2) in cancer progression and prognosis has been reported in several types of tumors. However, its role in esophageal carcinoma (EC) remains unknown. In the present study, TNFR2 expression in middle and lower thoracic esophageal squamous cell carcinoma (ESCC) was detected using immunohistochemistry (IHC). Chi-square test revealed that TNFR 2 was positively correlated with invasion depth, advanced clinical stage and low differentiation degree. Furthermore, survival analysis revealed that TNFR2 was positively correlated with poor overall survival (OS). Moreover, univariate COX regression analysis revealed that clinical stage, lymph node involvement, and invasion depth can affect the OS of ESCC patients, while multivariate COX regression analysis revealed that lymph node involvement and invasion depth can affect the OS of ESCC patients. In middle thoracic ESCC patients, TNFR2 was positively correlated with invasion depth, advanced clinical stage and poor OS. Furthermore, univariate and multivariate COX regression analysis both revealed that clinical stage, lymph node involvement, and invasion depth can affect OS. In lower thoracic ESCC patients, TNFR2 was positively correlated with low differentiation degree. Furthermore, the positive correlation of TNFR2 with poor OS did not reach statistical significance. In addition,
\end{abstract}

Correspondence to: Mr. Wei Wang, Pathology Department, Affiliated Hospital of Jining Medical University, 89 Guhuai Road, Jining, Shandong 272029, P.R. China

E-mail:wangwei1985@csu.edu.cn

Mrs. Zifeng Liu, Digestive Department, Affiliated Hospital of Jining Medical University, 89 Guhuai Road, Jining, Shandong 272029, P.R. China

E-mail: liuzifengde@126.com

Key words: esophageal carcinoma, esophageal squamous cell carcinoma, tumor necrosis factor receptor 2, immunohistochemistry, overall survival univariate $\mathrm{COX}$ regression analysis revealed that only lymph node involvement could affect OS. All the results suggest that TNFR2 can play an important role in the progression and poor prognosis of ESCC patients. Moreover, the role of TNFR2 in the prognosis of middle thoracic ESCC patients was earlier and stronger than in lower thoracic ESCC patients.

\section{Introduction}

Esophageal carcinoma (EC) is one of the most common malignant tumors worldwide, which is eighth in incidence and sixth in leading cause of cancer-related deaths $(1,2)$. Esophageal squamous cell carcinoma (ESCC) accounts for nearly $90 \%$ of EC cases in developing countries, especially in China (2). It is usually characterized by insidious early symptoms, lack of specific markers for diagnosis and evaluating prognosis, and poor prognosis (3). Despite its improvement in early detection and treatment in recent years, the overall survival (OS) of advanced ESCC patients remains poor, with a $<30 \%$ five-year survival rate in China (4). Hence, it is necessary to find more efficient targets that can be used for the diagnosis and treatment of ESCC patients.

According to the different locations of primary cancers, ESCC can be divided into four types: Cervical ESCC, upper thoracic ESCC, middle thoracic ESCC, and lower thoracic ESCC (5). The incidence of cervical and upper thoracic ESCC is much smaller than that of middle and lower thoracic ESCC (6). Moreover, the biological behavior of cervical and upper thoracic ESCC is closer to head and neck squamous cell carcinoma, rather than ESCC $(5,7,8)$. Hence, studies on middle and lower thoracic ESCC would be more meaningful for EC research.

Tumor necrosis factor receptor (TNFR) is composed of two members: tumor necrosis factor receptor 1 (TNFR1) and tumor necrosis factor receptor 2 (TNFR2). TNFR1 is widely expressed in different kinds of cells, and can mediate apoptosis induced by tumor necrosis factor- $\alpha$ (TNF- $\alpha$ ) (9). Different to TNFR1 due to the lack of a cytoplasmic death domain (DD), TNFR2 cannot activate the apoptotic machinery of cells, but can play important roles in bone healing, anti-inflammation and immune regulation through binding to TNF- $\alpha$ (10-12). 
In recent years, with deeper and more extensive studies on cancer, the high expression and promotion roles of TNFR2 have been reported in several types of tumors, such as ovarian cancer $(13,14)$ and breast cancer $(15)$. However, the clinical significance of TNFR2 in EC remains unknown.

In the present study, TNFR2 expression was detected in 431 tissue specimens obtained from ESSC patients by immunohistochemistry (IHC) staining, and the positive correlation of TNFR 2 with the progression and poor prognosis of the total cases was proven. Next, the clinical significance of TNFR2 in middle and lower thoracic ESCC was studied. Finally, COX regression analysis was performed to confirm the factors that can affect the prognosis of ESCC patients.

\section{Materials and methods}

Collection of tissue samples. Approved by the Ethics Committee of the Affiliated Hospital of Jining Medical University (Jining, China), we retrospectively selected 431 primary ESCC specimens from EC patients who had surgical removal from 2008 to 2014 in Affiliated Hospital of Jining Medical University. The inclusion criteria and exclusion criteria of this study were simple: i) patients with middle or lower ESCC; and ii) patients did not receive chemotherapy, radiotherapy or immunomodulatory therapy before surgery. Follow-up of outpatients was performed by telephone and the ending time was December, 2016.

IHC staining and scoring. ESCC wax samples were collected and cut into slides of $4 \mu \mathrm{m}$ thickness for hematoxylin and eosin (H\&E) staining. After H\&E staining, tumor regions were marked under microscope and tumor tissues were taken away using a trocar. Then many tumor tissues from different samples were embeded into one paraffin block. The paraffin block were cut into $4 \mu \mathrm{m}$ thickness and deparaffinized in xylene and rehydrated in graded ethanol, then boiled in $10 \mathrm{mmol} / 1$ citrate buffer $\left(\mathrm{pH} 6.0\right.$ ) for $3 \mathrm{~min}$ at $100^{\circ} \mathrm{C}$ for antigen unmasking. Then the sections were immersed in $3 \%$ $\mathrm{H}_{2} \mathrm{O}_{2}$ for 10 min to block the endogenous peroxidase and in goat serum blocking solution for $15 \mathrm{~min}$ to block non-specific antigens. After incubated at room temperature for $2 \mathrm{~h}$ in primary antibody of TNFR2 (1:400; Proteintech Group Inc., Chicago, IL, USA), sections were washed with PBS and incubated in HRP goat anti-rabbit/mouse IgG polymer (Maixin Biotechnology Development Co., Ltd., Fuzhou, China) at room temperature for $30 \mathrm{~min}$. Finally, slides were stained with 3,3'-diaminobenzidine and counterstained with hematoxylin. The scoring process was performed by two independent pathologists who were blind to clinical parameters and clinical outcomes of patients. The percentage of stained cells was evaluated at x400 magnification in at least 5 random fields. The proportion score represented the estimated fraction of positive staining tumor cells $(0 \leq 25 \%$; $26 \% \leq 1 \leq 50 \% ; 51 \% \leq 2 \leq 75 \% ; 3>75 \%$ ). The intensity score represented the estimated average staining intensity of positive tumor cells ( 0 , negative; 1 , weak; 2 , moderate; and 3 , strong). The expression level of TNFR2 was evaluated using the product of proportion score and intensity score at five fields and mean value was obtained ( $\leq 4$ as low expression, $>4$ as high expression).

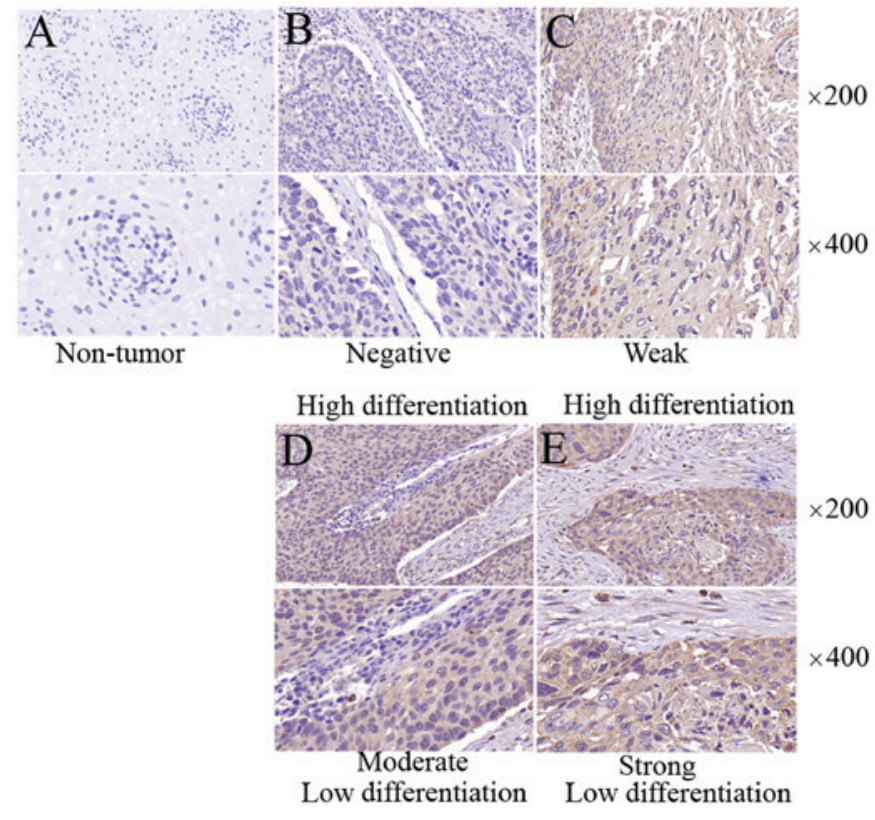

Figure 1. TNFR2 expression in ESCC tissue. (A) TNFR2 expression in non-tumor esophageal tissue; (B) negative expression of TNFR2 in ESCC tissue with high differentiation; (C) weak expression of TNFR2 in ESCC tissue with high differentiation; (D) moderate expression of TNFR2 in ESCC tissue with low differentiation; (E) high expression of TNFR2 in ESCC tissue with low differentiation. TNFR2, tumor necrosis factor receptor 2; ESCC, esophageal squamous cell carcinoma.

Statistical analysis. SPSS 11.0 software (SPSS, Inc., Chicago, IL, USA) was used for statistical analysis. The association between the expression of TNFR2 and clinical parameters was analyzed using the Chi-square test. Survival curves were drawn using the Kaplan-Meier method and compared using the log-rank test. Cox's proportional hazards regression model was performed to identify factors which can affect the OS of ESCC patients. $\mathrm{P}<0.05$ was considered to indicate a statistically significant difference.

\section{Results}

In the total cases, TNFR2 was positively correlated with invasion depth, advanced clinical stage, low differentiation degree and poor OS. A total of 431 specimens from different ESCC patients were collected and stained using IHC to detect TNFR2 expression, higher than non-tumor esophageal tissues (Fig. 1). All ESCC cases were divided into two groups including low expression of TNFR2 group and high expression of TNFR2 group. As shown in Table I, in the low expression of TNFR 2 group, only 119 out of 192 cases had an invasion depth greater than the muscularis, which was much less than 187 out of 239 cases in the high expression of TNFR2 group, and the difference was statistically significant $(\mathrm{P}<0.001)$. Furthermore, 129 out of 192 cases were at stage III, which was much less than 184 out of 239 cases in the high expression of TNFR2 group, and the difference was statistically significant $(\mathrm{P}=0.03)$. Moreover, 88 out of 192 cases has a low differentiation degree, which was much less than 143 out of 239 cases in the high expression of TNFR2 group, and the difference was statistically significant $(\mathrm{P}=0.005)$. Otherwise, there was no significant difference 
Table I. Correlation of TNFR2 with clinical parameters of the patients with total ESCC.

\begin{tabular}{|c|c|c|c|c|}
\hline \multirow[b]{2}{*}{ Clinical parameters } & \multirow[b]{2}{*}{ Cases } & \multicolumn{2}{|c|}{ TNFR2 } & \multirow[b]{2}{*}{ P-value } \\
\hline & & Low (192) & High (239) & \\
\hline \multicolumn{5}{|l|}{ Age } \\
\hline$\leq 60$ & 195 & 92 & 103 & 0.331 \\
\hline$>60$ & 236 & 100 & 136 & \\
\hline \multicolumn{5}{|l|}{ Sex } \\
\hline Male & 245 & 106 & 139 & 0.558 \\
\hline Female & 186 & 86 & 100 & \\
\hline \multicolumn{5}{|l|}{ Invasion depth } \\
\hline$\leq$ Muscularis & 125 & 73 & 52 & $<0.001^{\mathrm{a}}$ \\
\hline$>$ Muscularis & 306 & 119 & 187 & \\
\hline \multicolumn{5}{|l|}{ Tumor size } \\
\hline$\leq 4 \mathrm{~cm}$ & 271 & 115 & 156 & 0.271 \\
\hline$>4 \mathrm{~cm}$ & 160 & 77 & 83 & \\
\hline \multicolumn{5}{|l|}{ Tumor location } \\
\hline Lower & 152 & 72 & 80 & 0.418 \\
\hline Middle & 279 & 120 & 159 & \\
\hline \multicolumn{5}{|l|}{ Clinical stage } \\
\hline $\mathrm{I} / \mathrm{II}$ & 118 & 63 & 55 & $0.030^{\mathrm{a}}$ \\
\hline III & 313 & 129 & 184 & \\
\hline \multicolumn{5}{|l|}{ Differentiation } \\
\hline Low & 231 & 88 & 143 & $0.005^{\mathrm{a}}$ \\
\hline Moderate/high & 200 & 104 & 96 & \\
\hline \multicolumn{5}{|c|}{ Lymph node involvement } \\
\hline No & 222 & 99 & 123 & 0.984 \\
\hline Yes & 209 & 93 & 116 & \\
\hline
\end{tabular}

${ }^{\mathrm{a}} \mathrm{P}<0.05$. TNFR2, tumor necrosis factor receptor 2 .

in age, gender, tumor size, tumor location and lymph node involvement between these two groups. In addition, in the low expression of TNFR2 group, follow-up was performed for 115 cases. A total of 53 cases died during the follow-up period, and the survival rate was $53.91 \%$. In the high expression of TNFR 2 group, follow-up was performed in 113 cases. A total of 77 cases died during the follow-up period, and the survival rate was $31.86 \%$ (Fig. 2A). The Kaplan-Meier analysis revealed that OS in the high expression of TNFR2 group was worse, compared with that in the low expression of TNFR 2 group, and the difference was statistically significant $(\mathrm{P}=0.003$; Fig. 2B).

In middle thoracic ESCC patients, TNFR2 was positively correlated with invasion depth, advanced clinical stage and poor OS. The middle thoracic esophagus is the most common location of ESCCs. The 279 middle thoracic ESCC cases were divided into two groups: Low expression of TNFR2 group ( $n=120)$ and high expression of TNFR2 group $(n=159)$. As shown in Table II, in the low expression of TNFR 2 group, only 73 out of 120 cases had an invasion depth greater than the muscularis, which was much less than 127 out of 159 cases in the high expression of TNFR2 group, and the difference was statistically significant $(\mathrm{P}=0.001)$. Furthermore, 77 out of 120 cases were at stage III, which was much less than 125 out of 159 cases in the high expression of TNFR2 group, and the difference was statistically significant $(\mathrm{P}=0.01)$. In low expression of TNFR2 group, follow-up was performed in 65 cases. A total of 27 cases died during the follow-up period, and the survival rate was $58.46 \%$. In the high expression of TNFR2 group, follow-up was performed in 75 cases. A total of 52 cases died during the follow-up period, and the survival rate was $30.67 \%$ (Fig. 2C). The Kaplan-Meier analysis revealed that OS in the high expression of TNFR2 group was worse than that in the low expression of TNFR2 group, and the difference was statistically significant $(\mathrm{P}=0.002$; Fig. 2D).

In lower thoracic ESCC patients, TNFR2 was positively correlated with low differentiation degree. Lower thoracic esophagus is the second common location of ESCCs. The 152 lower thoracic ESCC cases were divided into two groups: low expression of TNFR2 group $(n=72)$ and high expression of TNFR2 group $(n=80)$. As shown in Table III, in the low expression of TNFR 2 group, only 33 out of 72 cases had a low differentiation degree, which was much less than 52 out of 
Table II. Correlation of TNFR2 with clinical parameters of patients with middle thoracic ESCC.

TNFR2

\begin{tabular}{|c|c|c|c|c|}
\hline \multirow{2}{*}{ Clinical parameters } & \multirow[b]{2}{*}{ Cases } & & \multirow[b]{2}{*}{ P-value } \\
\hline & & Low (120) & High (159) & \\
\hline \multicolumn{5}{|l|}{ Age } \\
\hline$\leq 60$ & 126 & 56 & 70 & \multirow[t]{2}{*}{0.716} \\
\hline$>60$ & 153 & 64 & 89 & \\
\hline \multicolumn{5}{|l|}{ Sex } \\
\hline Male & 212 & 91 & 121 & \multirow[t]{2}{*}{0.959} \\
\hline Female & 67 & 29 & 38 & \\
\hline \multicolumn{5}{|l|}{ Invasion depth } \\
\hline$\leq$ Muscularis & 79 & 47 & 32 & \multirow[t]{2}{*}{$0.001^{\mathrm{a}}$} \\
\hline$>$ Muscularis & 200 & 73 & 127 & \\
\hline \multicolumn{5}{|l|}{ Tumor size } \\
\hline$\leq 4 \mathrm{~cm}$ & 175 & 71 & 104 & \multirow[t]{2}{*}{0.318} \\
\hline$>4 \mathrm{~cm}$ & 104 & 49 & 55 & \\
\hline \multicolumn{5}{|l|}{ Clinical stage } \\
\hline $\mathrm{I} / \mathrm{II}$ & 77 & 43 & 34 & \multirow[t]{2}{*}{$0.01^{\mathrm{a}}$} \\
\hline III & 202 & 77 & 125 & \\
\hline \multicolumn{5}{|l|}{ Differentiation } \\
\hline Low & 146 & 55 & 91 & \multirow[t]{2}{*}{0.07} \\
\hline Moderate/high & 133 & 65 & 68 & \\
\hline \multicolumn{5}{|c|}{ Lymph node involvement } \\
\hline No & 154 & 69 & 85 & \multirow[t]{2}{*}{0.544} \\
\hline Yes & 125 & 51 & 74 & \\
\hline
\end{tabular}

${ }^{\mathrm{a}} \mathrm{P}<0.05$. ESCC, esophageal squamous cell carcinoma; TNFR2, tumor necrosis factor receptor 2.

80 cases in the high expression of TNFR2 group, and the difference was statistically significant $(\mathrm{P}=0.022)$. In low expression of TNFR 2 group, follow-up was performed in 50 cases. A total of 26 cases died during the follow-up period, and the survival rate was $48.00 \%$. In the high expression of TNFR2 group, follow-up was performed in 38 cases. A total of 24 cases died during the follow-up period, and the survival rate was $36.84 \%$ (Fig. 2E). The Kaplan-Meier analysis revealed that OS in the high expression of TNFR2 group was worse than that in the low expression of TNFR2 group, but the difference was not statistically significant $(\mathrm{P}=0.459$; Fig. $2 \mathrm{~F})$.

COX regression analysis of factors which can affect OS of ESCC patients. In order to further investigate the potential factors that can influence the prognosis of patients, COX regression analysis was performed. In the total cases, the univariate COX regression analysis revealed that clinical stage, lymph node involvement, and invasion depth could affect the OS of ESCC patients, and the difference was statistically significant $(\mathrm{P}=0.01,<0.001$ and 0.001$)$. The multivariate COX regression analysis revealed that lymph node involvement and invasion depth could affect the OS of ESCC patients, and the difference was statistically significant $(\mathrm{P}<0.001$ and 0.048 ; Table IV). In middle thoracic ESCC patients, the univariate COX regression analysis revealed that clinical stage, lymph node involvement, and invasion depth could affect the OS of
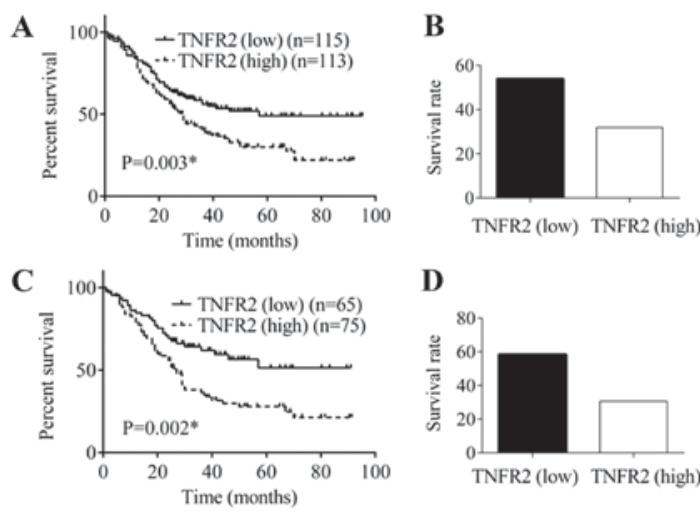

D
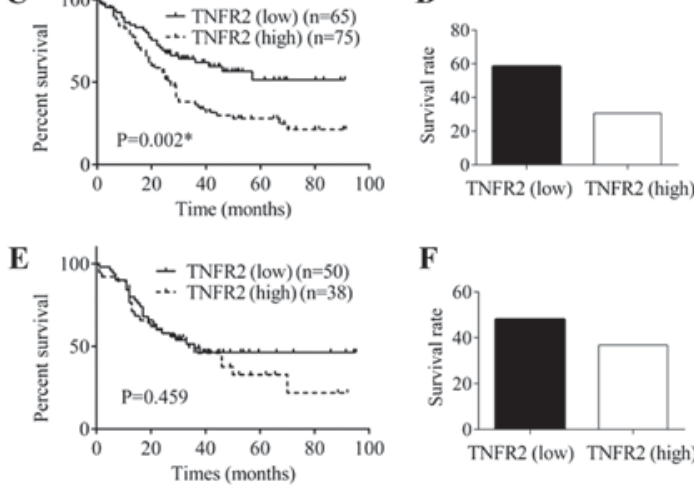

F

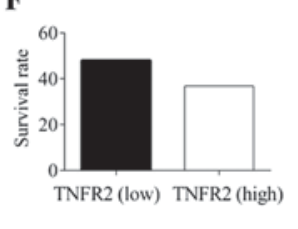

Figure 2. Survival analysis of total cases, middle thoracic ESCC cases and lower thoracic ESCC cases. (A) Comparison of OS among the different groups of the total cases; (B) comparison of survival rates among the different groups of the total cases; (C) comparison of OS among the different groups of middle thoracic ESCC cases; (D) comparison of survival rates among the different groups of middle thoracic ESCC cases; (E) comparison of OS among the different groups of lower thoracic ESCC cases; (F) comparison of survival rates between the different groups of lower thoracic ESCC cases. OS, overall survival; ESCC, esophageal squamous cell carcinoma. 
Table III. Correlation of TNFR2 with clinical parameters of patients with lower thoracic ESCC.

\begin{tabular}{|c|c|c|c|c|}
\hline \multirow[b]{2}{*}{ Clinical parameters } & \multirow[b]{2}{*}{ Cases } & \multicolumn{2}{|c|}{ TNFR2 } & \multirow[b]{2}{*}{ P-value } \\
\hline & & Low (72) & High (80) & \\
\hline \multicolumn{5}{|l|}{ Age } \\
\hline$\leq 60$ & 69 & 36 & 33 & \multirow[t]{2}{*}{0.329} \\
\hline$>60$ & 83 & 36 & 47 & \\
\hline \multicolumn{5}{|l|}{ Sex } \\
\hline Male & 33 & 15 & 18 & \multirow[t]{2}{*}{0.846} \\
\hline Female & 119 & 57 & 62 & \\
\hline \multicolumn{5}{|l|}{ Invasion depth } \\
\hline$\leq$ Muscularis & 46 & 26 & 20 & \multirow[t]{2}{*}{0.159} \\
\hline$>$ Muscularis & 106 & 46 & 60 & \\
\hline \multicolumn{5}{|l|}{ Tumor size } \\
\hline$\leq 4 \mathrm{~cm}$ & 96 & 44 & 52 & \multirow[t]{2}{*}{0.736} \\
\hline$>4 \mathrm{~cm}$ & 56 & 28 & 28 & \\
\hline \multicolumn{5}{|l|}{ Clinical stage } \\
\hline $\mathrm{I} / \mathrm{II}$ & 41 & 20 & 21 & \multirow[t]{2}{*}{0.857} \\
\hline III & 111 & 52 & 59 & \\
\hline \multicolumn{5}{|l|}{ Differentiation } \\
\hline Low & 85 & 33 & 52 & \multirow[t]{2}{*}{$0.022^{\mathrm{a}}$} \\
\hline Moderate/high & 67 & 39 & 28 & \\
\hline \multicolumn{5}{|c|}{ Lymph node involvement } \\
\hline No & 68 & 30 & 38 & \multirow[t]{2}{*}{0.516} \\
\hline Yes & 84 & 42 & 42 & \\
\hline
\end{tabular}

${ }^{\mathrm{a}} \mathrm{P}<0$. 05. ESCC, esophageal squamous cell carcinoma; TNFR2, tumor necrosis factor receptor 2.

Table IV. Univariate and multivariate analysis identify factors influencing the overall survival of patients with total ESCC.

\begin{tabular}{|c|c|c|c|c|c|c|}
\hline \multirow[b]{2}{*}{ Variable } & \multicolumn{3}{|c|}{ Univariate analysis } & \multicolumn{3}{|c|}{ Multivariate analysis } \\
\hline & HR & $95 \% \mathrm{CI}$ & P-value & HR & $95 \% \mathrm{CI}$ & P-value \\
\hline Sex & 0.845 & $0.566-1.284$ & 0.430 & & & \\
\hline Age & 1.107 & $0.784-1.562$ & 0.564 & & & \\
\hline Clinical stage & 0.585 & $0.389-0.881$ & $0.010^{\mathrm{a}}$ & 0.586 & $0.205-1.679$ & 0.320 \\
\hline Differentiation degree & 1.133 & $0.803-1.598$ & 0.477 & & & \\
\hline Location & 0.999 & $0.702-1.423$ & 0.996 & & & \\
\hline Size & 1.069 & $0.747-1.528$ & 0.717 & & & \\
\hline Lymph node involvement & 0.459 & $0.32-0.659$ & $<0.001^{\mathrm{a}}$ & 2.058 & $1.43-2.961$ & $<0.001^{\mathrm{a}}$ \\
\hline Invasion depth & 0.511 & $0.339-0.77$ & $0.001^{\mathrm{a}}$ & 2.882 & $1.007-8.245$ & $0.048^{\mathrm{a}}$ \\
\hline
\end{tabular}

${ }^{\mathrm{a}} \mathrm{P}<0.05$. HR, hazard ratio; CI, confidence interval; ESCC, esophageal squamous cell carcinoma.

ESCC patients, and the difference was statistically significant $(\mathrm{P}=0.026,0.012$, and 0.002$)$. The multivariate $\mathrm{COX}$ regression analysis revealed that clinical stage, lymph node involvement, and invasion depth could affect the OS of ESCC patients, and the difference was statistically significant $(\mathrm{P}=0.013,0.031$, and 0.001; Table V). In lower thoracic ESCC patients, the univariate COX regression analysis revealed that only lymph node involvement could affect the OS of ESCC patients, and the difference was statistically significant $(\mathrm{P}<0.001$; Table VI).

\section{Discussion}

ESCC is a type of cancer that originates from esophageal squamous epithelial cells. Its pathogenesis is not only hereditary, 
Table V. Univariate and multivariate analysis identify factors influencing the overall survival of patients with middle thoracic ESCC.

\begin{tabular}{|c|c|c|c|c|c|c|}
\hline \multirow[b]{2}{*}{ Variable } & \multicolumn{3}{|c|}{ Univariate analysis } & \multicolumn{3}{|c|}{ Multivariate analysis } \\
\hline & HR & $95 \% \mathrm{CI}$ & P-value & HR & $95 \% \mathrm{CI}$ & P-value \\
\hline Sex & 0.817 & $0.488-1.369$ & 0.443 & & & \\
\hline Age & 0.889 & $0.573-1.380$ & 0.600 & & & \\
\hline Clinical stage & 0.55 & $0.325-0.93$ & $0.026^{\mathrm{a}}$ & 0.202 & $0.057-0.713$ & $0.013^{\mathrm{a}}$ \\
\hline Differentiation degree & 1.186 & $0.764-1.84$ & 0.447 & & & \\
\hline Size & 1.188 & $0.747-1.888$ & 0.467 & & & \\
\hline Lymph node involvement & 0.559 & $0.356-0.878$ & $0.012^{\mathrm{a}}$ & 1.656 & $1.048-2.617$ & $0.031^{\mathrm{a}}$ \\
\hline Invasion depth & 0.415 & $0.239-0.721$ & $0.002^{\mathrm{a}}$ & 9.932 & 2.673-36.911 & $0.001^{\mathrm{a}}$ \\
\hline
\end{tabular}

${ }^{\mathrm{a}} \mathrm{P}<0.05$. HR, hazard ratio; CI, confidence interval; ESCC, esophageal squamous cell carcinoma.

Table VI. Univariate analysis identify factors influencing the overall survival of patients with lower thoracic ESCC.

\begin{tabular}{lclc}
\hline & \multicolumn{3}{c}{ Univariate analysis } \\
\cline { 2 - 4 } Variables & HR & \multicolumn{1}{c}{$95 \%$ CI } & P-value \\
\hline Sex & 0.893 & $0.433-1.839$ & 0.758 \\
Age & 1.607 & $0.92-2.808$ & 0.096 \\
Clinical stage & 0.647 & $0.337-1.242$ & 0.191 \\
Differentiation degree & 1.064 & $0.608-1.861$ & 0.828 \\
Size & 0.899 & $0.51-1.584$ & 0.712 \\
Lymph node involvement & 0.333 & $1.181-0.612$ & $<0.001^{\text {a }}$ \\
Invasion depth & 0.687 & $0.369-1.277$ & 0.235 \\
\hline
\end{tabular}

${ }^{\mathrm{a} P}<0.05$. HR, hazard ratio; CI, confidence interval; ESCC, esophageal squamous cell carcinoma.

but can be induced by unhealthy lifestyles, such as eating food that contains nitrite, drinking, smoking and so on $(16,17)$. Hence, its incidence in males is significantly higher than that in females (18). In the present study, the number of enrolled males $(n=245)$ was greater than females $(n=186)$, which is consistent with the incidence of ESCC between different genders. According to different location of primary cancers, ESCC can be divided into four types. Middle thoracic ESCCs are tumors that range from the azygos vein to the inferior pulmonary vein and its incidence ranks first. Lower thoracic ESCCs are tumors that range from the inferior pulmonary vein to the lower esophageal sphincter and its incidence ranks second (5). In these 431 cases, middle thoracic ESCC cases $(n=279)$ were greater than lower thoracic ESCC cases $(n=152)$. This is consistent with the different incidences of middle and lower thoracic ESCCs (6).

TNFR2 protein is encoded by the tumor necrosis factor superfamily 1B (TNFRSF1B) gene, which weights $75 \mathrm{kDa}$ (19). Its high expression and potential in maintaining the malignant biological behaviors of cells, metastasis (20), invasion (21) and proliferation (22) have been reported in several types of tumors. Moreover, it was found that TNFR2 could promote the transformation of resident fibroblasts to cancer associated fibroblasts (CAFs) (23). Furthermore, it is well-known that CAFs can contribute to migration, invasion and metastasis, and even prevent differentiation and induce the stemness of tumor cells $(24,25)$. In the present study, the investigators attempted to confirm the clinical significance of TNFR2 in ESCCs. In the total cases, it was found that TNFR 2 was positively correlated with invasion depth, advanced clinical stage and low differentiation degree. In middle thoracic ESCC samples, it was found that TNFR2 was also positively correlated with invasion depth and advanced clinical stage. The correlation of TNFR2 with differentiation did not reach a statistical significance, but a positive trend was found. This supports the results from the study of the total cases. In lower thoracic ESCC samples, a positive correlation between TNFR2 and low differentiation was also found, and this supplied further support to the roles of TNFR2 in differentiation. All these results confirm the role of TNFR2 in ESCC progression, and are consistent with the roles of TNFR 2 in the malignant biological behaviors of tumor cells, such as in promoting migration, invasion, preventing differentiation and inducing stemness, as previously reported (20-25).

The roles of TNFR2 in prognosis have been reported by several researchers, but the results were inconsistent. Heemann $\mathrm{C}$ and Nakamura $\mathrm{N}$ reported that the circulating level of TNFR2 was associated with poor outcome of patients with peripheral T-cell non-Hodgkin lymphoma and diffuse large B-cell lymphoma $(26,27)$. However, in 2005, Mestiri $\mathrm{S}$ reported that the 196R-TNFRII allele revealed a significant association with increased OS and disease-free survival in breast carcinoma patients (28). In the present study, regardless of whether it pertains to the total cases or middle thoracic ESCC patients, the result revealed that TNFR2 was positively correlated with poor OS. This is consistent with the reports of Heemann $\mathrm{C}$ and Nakamura $\mathrm{N}$, and was in line with the roles of TNFR2 in the malignant behaviors of tumor cells, which was previously reported. However, this was not consistent with the report of Mestiri S. This can be explained by the differences in tumor origin or races. Moreover, the difference in OS between the two groups began vary early, which was nearly from six months. Otherwise, in lower thoracic ESCC patients, although 
the prognosis of patients in the high expression of TNFR2 group was poorer than in the low expression of TNFR2 group, the difference was not significant. Particularly at the early period (before 46 months), there was nearly no difference in OS between the two groups, and the difference was mainly found at the late period (46 months later). This suggests that the role of TNFR2 in the prognosis of lower thoracic ESCC might be weaker and later than that of middle thoracic ESCC.

ESCC is a rapidly evolving disease, and its prognosis can be affected by clinical stage, tumor size, lymph node involvement, and so on. Advanced clinical stage usually leads to more malignant behaviors in tumor cells or longer time intervals in cancer progression, and this can often result in poor prognosis $(29,30)$. Lymph node involvement and deeper invasion usually imply the stronger invasion ability of tumor cells, and are commonly used as criteria for evaluating for clinical stage and progression (31-33). In the total cases, the univariate COX regression analysis revealed that clinical stage, lymph node involvement, and invasion depth could significantly affect the OS of ESCC patients. Moreover, the multivariate COX regression analysis revealed that both lymph node involvement and invasion depth could significantly affect the OS of ESCC patients. This suggests that clinical stage, lymph node involvement, and invasion depth can be treated as independent prognostic factors of ESCC. For middle thoracic ESCCs, clinical stage, lymph node involvement and invasion depth were proven as independent prognostic factors. However, in lower thoracic ESCCs, only lymph node involvement could significantly affect the OS of ESCC patients. This might be attributed to the reason that lower thoracic ESCC was closely adjacent to esophageal and cardiac lymph nodes, making it easier for lymph node involvement, or attributed to the limited specimens in the present study.

Another TNFR, TNFR1 is not studied in this paper. Its role in tumor has been reported previously. Zhao $\mathrm{Y}$ reported that downregulating TNFR1 could suppress growth of breast cancer cells (34). But, You BR reported that down-regulation of TNFR1 suppressed apoptosis in TNF- $\alpha$ treated lung cancer cells (35). In view of different roles of TNFR1 in different types of tumors, it is hard to predict the clinical significance of TNFR1 in ESCC. The role of TNFR1 in tumor progression and prognosis still needs our later study.

Of course, there are also some limitations in our study. All cases in our study are mainly from nearby areas, so the data is regional and the result is limited. Multi-center study would supply more universal results. In addition, we only showed clinical significance of TNFR2 here, no cell and animal experiments was performed. Further experiments on cell, animal and molecular levels would enrich our undersatanding about roles of TNFR2 in ESCC.

In conclusion, the clinical significance of TNFR2 in middle and lower thoracic ESCCs was confirmed, which enriched our knowledge on the roles of TNFR2 in tumors. TNFR2 might be used as a good prognostic factor of ESCC. Moreover, it can also be used as a therapeutic target. As our deeper study, more efficient target drug forTNFR2 is also possible. Of course, this still needs hard work.

\section{Acknowledgements}

Not applicable.

\section{Funding}

This study was funded by the Doctor Foundation of the Affiliated Hospital of Jining Medical University (grant no. 2016-BS-005, 2016-BS-002), the Natural Science foundation of Shandong Provience, China(ZR2016HQ28).

\section{Availability of data and materials}

The datasets used and/or analyzed during the current study are available from the corresponding author on reasonable request.

\section{Authors' contributions}

DY and ZFL designed the study and wrote the manuscript. RDL, HLW and JYW analyzed the data. YL, HBW and WW collected the tissue specimens and performed immunohistochemistry staining.

\section{Ethics approval and consent to participate}

The present study was approved by the Ethics Committee of the Affiliated Hospital of Jining Medical University.

\section{Consent for publication}

Not applicable.

\section{Competing interests}

The authors declare that they have no competing interests.

\section{References}

1. Feng J, Qi B, Guo L, Chen LY, Wei XF, Liu YZ and Zhao BS: miR-382 functions as a tumor suppressor against esophageal squamous cell carcinoma. World J Gastroenterol 23: 4243-4251, 2017.

2. Han G, Wu Z, Zhao N, Zhou L, Liu F, Niu F, Xu Y and Zhao X: Overexpression of stathmin plays a pivotal role in the metastasis of esophageal squamous cell carcinoma. Oncotarget 8: 61742-61760,2017.

3. Jiang Q, Chen J, Zhang B, Niu J and He Y: Prognostic Significance of periostin and mammalian target of rapamycin (mTOR) in locally advanced esophageal squamous cell carcinoma. Med Sci Monit 23: 3200-3208, 2017

4. Dong Q, Fu L, Zhao Y, Liu Y, Li Q, Qiu X and Wang E: Derlin-1 is a target to improve radiotherapy effect of esophageal squamous cell carcinoma. Oncotarget 8: 55135-55146, 2017.

5. Li X, Zhao L, Zhang W, Yang C, Lian Z, Wang S, Liu N, Pang Q, Wang $\mathrm{P}$ and $\mathrm{Yu}$ J: Prognostic value of supraclavicular nodes and upper abdominal nodes metastasis after definitive chemoradiotherapy for patients with thoracic esophageal squamous cell carcinoma. Oncotarget 8: 65171-67185, 2017.

6. Deng W, Wang Q, Xiao Z, Tan L, Yang Z, Zhou Z, Liu N, Pang Q, Wang $\mathrm{P}, \mathrm{Yu} \mathrm{J}$, et al: A prognostic nomogram for overall survival after neoadjuvant radiotherapy or chemoradiotherapy in thoracic esophageal squamous cell carcinoma: a retrospective analysis. Oncotarget 8: 41102-41112, 2017.

7. Tachimori Y, Nagai Y, Kanamori N, Hokamura N and Igaki H: Pattern of lymph node metastases of esophageal squamous cell carcinoma based on the anatomical lymphatic drainage system. Dis Esophagus 24: 33-38, 2011.

8. Merkow RP, Bilimoria KY, Keswani RN, Chung J, Sherman KL, Knab LM, Posner MC and Bentrem DJ: Treatment trends, risk of lymph node metastasis and outcomes for localized esophageal cancer. J Natl Cancer Inst 106: dju133, 2014.

9. Miao X, Huang Y, Liu TT, Guo R, Wang B, Wang XL, Chen LH, Zhou Y, Ji RR and Liu T: TNF- $\alpha /$ TNFR1 signaling is required for the full expression of acute and chronic itch in mice via peripheral and central mechanisms. Neurosci Bull 34: 42-53, 2018. 
10. Zhao YP, Tian QY, Frenkel S and Liu CJ: The promotion of bone healing by progranulin, a downstream molecule of BMP-2, through interacting with TNF/TNFR signaling. Biomaterials 34 : 6412-6421, 2013.

11. Tang W, Lu Y, Tian QY, Zhang Y, Guo FJ, Liu GY, Syed NM, Lai Y, Lin EA, Kong L, et al: The growth factor progranulin binds to TNF receptors and is therapeutic against inflammatory arthritis in mice. Science 332: 478-484, 2011.

12. Martin EM, Remke A, Pfeifer E, Polz J, Pietryga-Krieger A, Steffens-Weber D, Freudenberg MA, Mostböck S and Männel DN TNFR 2 maintains adequate IL-12 production by dendritic cells in inflammatory responses by regulating endogenous TNF levels. Innate Immun 20: 712-720, 2014.

13. Ferrarelli LK: Locking TNFR 2 to kill ovarian cancer. Science 355: 257-258, 2017.

14. Chen X and Oppenheim JJ: Targeting TNFR2, an immune checkpoint stimulator and oncoprotein, is a promising treatment for cancer. Sci Signal 10: eaal2328, 2017.

15. Yang $\mathrm{F}$, Zhao $\mathrm{N}$ and $\mathrm{Wu} \mathrm{N}$ : TNFR2 promotes Adriamycin resistance in breast cancer cells by repairing DNA damage. Mol Med Rep 16: 2962-2968, 2017.

16. Spreafico A, Coate L, Zhai R, Xu W, Chen ZF, Chen Z, Patel D, Tse B, Brown MC, Heist RS, et al: Early adulthood body mass index, cumulative smoking and esophageal adenocarcinoma survival. Cancer Epidemiol 47: 28-34, 2017.

17. Choi YJ, Lee DH, Han K, Yoon H, Shin CM, Park YS and Kim N. Joint effects of low body mass index and alcohol consumption on developing esophageal squamous cell cancer: A korean nationwide population-based cohort study. Asian Pac J Cancer Preve 18: 1881-1887, 2017.

18. Short MW, Burgers KG and Fry VT: Esophageal cancer. Am Fam Physician 95: 22-28, 2017.

19. Xu F, Zhou G, Han S, Yuan W, Chen S, Fu Z, Li D, Zhang H, Li D and Pang D: Association of TNF- $\alpha$, TNFRSF1A and TNFRSF1B gene polymorphisms with the risk of sporadic breast cancer in northeast Chinese Han women. PLoS One 9: e101138, 2014.

20. Jöhrer K, Janke K, Krugmann J, Fiegl M and Greil R: Transendothelial migration of myeloma cells is increased by tumor necrosis factor (TNF)- $\alpha$ via TNF receptor 2 and autocrine up-regulation of mcp-1. Clin Cancer Res 10: 1901-1910, 2004.

21. Tanimura Y, Kokuryo T, Tsunoda N, Yamazaki Y, Oda K, Nimura Y, Naing Mon N, Huang P, Nakanuma Y, Chen MF, et al: Tumor necrosis factor $\alpha$ promotes invasiveness of cholangiocarcinoma cells via its receptor, TNFR2. Cancer Lett 219: 205-213, 2005.

22. Yang D, Wang LL, Dong TT, Shen YH, Guo XS, Liu CY, Liu J, Zhang P, Li J and Sun YP: Progranulin promotes colorectal cancer proliferation and angiogenesis through TNFR2 Akt and ERK signaling pathways. Am J Cancer Res 5: 3085-3097, 2015.

23. Wang L, Yang D, Tian J, Gao A, Shen Y, Ren X, Li X, Jiang G and Dong T: Tumor necrosis factor receptor 2/AKT and ERK signaling pathways contribute to the switch from fibroblasts to CAFs by progranulin in microenvironment of colorectal cancer. Oncotarget 8: 26323-26333, 2017.

24. Geary LA, Nash KA, Adisetiyo H, Liang M, Liao CP, Jeong JH, Zandi E and Roy-Burman P: CAF-secreted annexin A1 induces prostate cancer cells to gain stem cell-like features. Mol Cancer Res 12: 607-621, 2014.
25. Kinugasa Y, Matsui T and Takakura N: CD44 expressed on cancer-associated fibroblasts is a functional molecule supporting the stemness and drug resistance of malignant cancer cells in the tumor microenvironment. Stem Cells 32: 145-156, 2014.

26. Heemann C, Kreuz M, Stoller I, Schoof N, von Bonin F, Ziepert M, Löffler M, Jung W, Pfreundschuh M, Trümper L and Kube D: Circulating levels of TNF receptor II are prognostic for patients with peripheral T-cell non-Hodgkin lymphoma. Clin Cancer Res 18: 3637-3647, 2012

27. Nakamura N, Goto N, Tsurumi H, Takemura M, Kanemura N, Kasahara S, Hara T, Yasuda I, Shimizu M, Sawada M, et al: Serum level of soluble tumor necrosis factor receptor 2 is associated with the outcome of patients with diffuse large B-cell lymphoma treated with the R-CHOP regimen. Eur J Haematol 91: 322-331, 2013.

28. Mestiri S, Bouaouina N, Ben Ahmed S and Chouchane L: A functional polymorphism of the tumor necrosis factor receptor-II gene associated with the survival and relapse prediction of breast carcinoma. Cytokine 30: 182-187, 2005.

29. Chai P, Tian J, Zhao D, Zhang H, Cui J, Ding K and Liu B: GSE1 negative regulation by miR-489-5p promotes breast cancer cell proliferation and invasion. Biochem Biophys Res Commun 471: 123-128, 2016

30. Richards P, Ward S, Morgan J, Lagord C, Reed M, Collins K and Wyld L: The use of surgery in the treatment of ER+ early stage breast cancer in England: Variation by time, age and patient characteristics. Eur J Surg Oncol 42: 489-496, 2016.

31. Yang J, Long Q, Li H, Lv Q, Tan Q and Yang X: The value of positive lymph nodes ratio combined with negative lymph node count in prediction of breast cancer survival. J Thorac Dis 9: 1531-1537, 2017.

32. Jutric Z, Grendar J, Hoen HM, Cho SW, Cassera MA, Newell PH, Hammill CW, Hansen PD and Wolf RF: Regional metastatic behavior of nonfunctional pancreatic neuroendocrine tumors: Impact of lymph node positivity on survival. Pancreas 46: 898-903, 2017.

33. Okura M, Yanamoto S, Umeda M, Otsuru M, Ota Y, Kurita H, Kamata T, Kirita T, Yamakawa N, Yamashita T, et al: Prognostic and staging implications of mandibular canal invasion in lower gingival squamous cell carcinoma. Cancer Med 5: 3378-3385, 2016.

34. Zhao Y, Yang F, Li W, Xu C, Li L, Chen L, Liu Y and Sun P: miR-29a suppresses MCF-7 cell growth by downregulating tumor necrosis factor receptor 1. Tumour Biol 39: 1010428317692264 , 2017.

35. You BR, Han BR and Park WH: Suberoylanilide hydroxamic acid increases anti-cancer effect of tumor necrosis factor- $\alpha$ through up-regulation of TNF receptor 1 in lung cancer cells. Oncotarget 8: 17726-17737, 2017.

This work is licensed under a Creative Commons Attribution-NonCommercial-NoDerivatives 4.0 International (CC BY-NC-ND 4.0) License. 